\section{Hexahromocyclododecane in Marine Species from the Western Scheldt Estuary: Diastereoisomer- and Enantiomer-Specific Accumulation}

KAREL JANÁK, *,† ADRIAN COVACI, * STEFAN VOORSPOELS, * AND GEORG BECHER ${ }^{\dagger}$

Division of Environmental Medicine,

Norwegian Institute of Public Health, P.O. Box 4404, Nydalen, NO-0403 Oslo, Norway, and Toxicological Center, University of Antwerp, Universiteitsplein 1, 2610 Wilrijk, Belgium

Hexabromocyclododecane (HBCD) is a widely used brominated flame retardant, which is increasingly reported in the environment. Here, we report on the diastereomeric and, for the first time, on the enantiomeric composition of HBCD in muscle and liver of several fish species caught in the Western Scheldt Estuary (The Netherlands). The total HBCD content (sum of $\alpha-, \beta$-, and $\gamma$-diastereoisomers), as well as the distribution of diastereoisomers and enantiomers, varied between the species. The levels of total HBCD (9-1110 $\mathrm{ng} / \mathrm{g}$ lipid weight) found in fish tissues were higher than those measured in fish from European rivers with no known point sources of HBCD but lower than in fish samples collected near factories producing or using HBCD. The concentrations of total HBCD expressed on a lipid weight basis were higher in liver than in muscle for bib and whiting, while in sole, HBCD had no preferential distribution between the tissues. A similar pattern for liver and muscle distribution was already observed for polybrominated diphenyl ethers (PBDEs) in these species. The $\alpha-H B C D$ diastereoisomer was most abundant in all fish samples with a higher contribution to the total HBCD levels in liver compared to muscle for bib and whiting. The $\gamma$-HBCD diastereoisomer accumulated less in liver than in muscle of sole, bib, and whiting. For the first time, enantiomer fractions were determined for HBCD diastereoisomers in liver of three fish species and in muscle of two fish species. A significant enrichment of the $(+) \alpha-H B C D$ enantiomer was found in whiting and bib liver samples. A high enantioselectivity has also been seen for the $\gamma$-HBCD diastereoisomer in whiting liver.

\section{Introduction}

Hexabromocyclododecane (HBCD) is an additive brominated flame retardant (BFR) used in polystyrene foams and upholstery textiles in percentages varying between 0.8 and $4 \%$ (I). In 2001, the world market demand for HBCD was at about 16700 tons from which about 9500 tons were consumed in Europe. These figures make HBCD the second

\footnotetext{
${ }^{*}$ Corresponding author phone: +47220425 80; fax: +472204 26 86; e-mail: karel.janak@fhi.no.

Norwegian Institute of Public Health.

¥University of Antwerp.

most used BFR in Europe, after tetrabromobisphenol A (1). Recently, the use of penta- and octamixtures of polybrominated diphenyl ethers (PBDEs) has been restricted in Europe (2). There are indications that HBCD is being used as a replacement for these BFRs (3).

Technical 1,2,5,6,9,10-HBCD is produced by bromination of cyclododecatriene $(\mathrm{CDT})(4,5)$. This process leads theoretically to a mixture of 16 stereoisomers (six pairs of enantiomers and four mesoforms). Bromination of cis, trans, trans-CDT yields three diastereomeric pairs of enantiomers as racemic mixtures (5), $\alpha-, \beta$-, and $\gamma$-HBCD (Figure 1). Further, two mesoforms have been isolated from a lowmelting, technical-grade HBCD mixture (4). The commercial mixtures consist mainly of the $\gamma$-HBCD diastereoisomer (ranging between 75 and $89 \%$ ), while the $\alpha$ - and $\beta$-HBCD are present in considerably lower amounts $(10-13 \%$ and $1-12 \%$, respectively) (6). HBCD is subject to thermal rearrangement at temperatures above $160^{\circ} \mathrm{C}$, resulting in a specific mixture of the three diastereoisomers $(78 \% \alpha-\mathrm{HBCD}, 13 \% \beta-\mathrm{HBCD}$, and $9 \% \gamma-\mathrm{HBCD}$ ), while decomposition becomes significant at temperatures above $200{ }^{\circ} \mathrm{C}(7)$. This rearrangement is independent of the starting isomer composition (6).

Substantial dissimilarities in the structure of the $\alpha-, \beta$, and $\gamma$-HBCD diastereoisomers might raise differences in polarity, dipole moment, and as already found, in solubility in water. Solubility of $\alpha-, \beta$-, and $\gamma$-HBCD in water was recently measured to be $48.8,14.7$, and $2.1 \mu \mathrm{g} / \mathrm{L}$, respectively ( 8 ). These different properties may result in distinctive rates of biological uptake and metabolism and could possibly explain the observed differences in their environmental behavior $(9$, 10). Once released into the environment and because of their low water solubility, it is likely that HBCD isomers will adsorb onto solid particles of sediment and soil (1). Its resistance to degradation together with a low estimated octanol-water partitioning coefficient $\left(\log K_{\mathrm{ow}}=5.6\right)$ makes $\mathrm{HBCD}$ potentially bioaccumulative in fatty tissues $(11,12)$.

Although little is known about the metabolism of HBCD diastereoisomers, there are indications of a relatively short half-life (13) and of a different biotransformation of HBCD isomers (14). However, the preliminary estimated half-lives for $\alpha$ - and $\beta$-HBCD diastereoisomers in juvenile rainbow trout (Oncorhynchus mykiss) were 136 and 53 days, respectively, suggesting that the metabolizing capacity of fish for $H B C D$ is limited and that there are differences in the absorption and detoxification rate between different diastereoisomers (9). There is also evidence for bioisomerization of HBCD diastereoisomers with a preferential formation of the $\alpha$-HBCD isomer; lower brominated cyclododecane metabolities could not be detected in fish from this study (10). In another experiment, $\alpha-\mathrm{HBCD}$ was not significantly biotransformed after $\mathbf{9 0} \mathrm{min}$ during the incubation of rat and harbor seal liver microsomes, while $\beta$ - and $\gamma$-HBCD diastereoisomers decreased to about one-third of the original value (14).

To get a better understanding of environmental fate and behavior of $\mathrm{HBCD}$ in biota, it is essential to get isomer specific data on HBCD levels. While the determination of BFRs, and in particular of PBDEs, was recently reviewed $(15,16)$, methods for analysis of HBCD have received much less attention. Most of the HBCD data generated in the past were obtained by gas chromatography/mass spectrometry (GC/ MS) and thus restricted to total HBCD levels. So far, GC/MS could not provide a separation of the individual HBCD diastereoisomers and a mixture of diastereoisomers elutes as a broad peak. As also follows from interlaboratory studies, the precision and accuracy ranges in the HBCD determination 

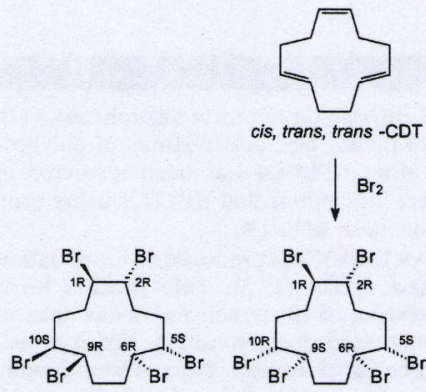

CAS $134237-50-6$

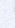

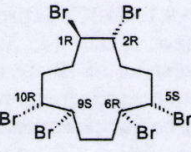

CAS 134237-51-7

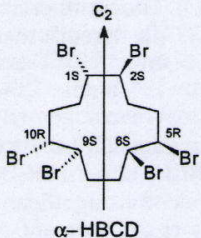

$\alpha-H B C D$
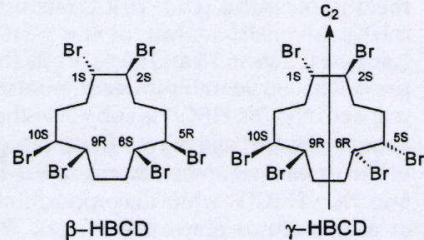

FIGURE 1. Stereochemical structures of the major HBCD isomers.

by GC/MS are larger compared to those obtained for PBDEs $(16,17)$. Recently, individual HBCD diastereoisomers could be analyzed in biota using reversed-phase liquid chromatography coupled with electrospray tandem mass spectrometric detection (LC/MS-MS) $(17,18)$

Moreover, the $\alpha-, \beta$-, and $\gamma$-HBCD diastereoisomers are chiral and thus may be present in the environment and biota as enantiomeric pairs. In general, a chiral pollutant is produced and released into the environment as racemate and remains as a racemic mixture as long as it is subjected only to achiral interactions, such as hydrolysis, photolysis, leaching, volatilization, and atmospheric deposition (18). However, alterations in the enantiomeric composition might occur if the chiral compound is subjected to biochemical processes that in most cases are stereospecific, for example, metabolization (19). The enantiomer fraction (EF) that is used to express the enantiomeric composition of pollutants (20) may differ between species and tissues and within populations (21). Consequently, the investigation of enantiomeric composition of HBCD in biota might be of great importance in understanding metabolization and degradation processes.

Recently, we have established methods based on reversedphase LC/MS-MS for the determination of HBCD diastereoisomers as well as for estimation of EFs for enantiomeric pairs of $\alpha_{-}, \beta_{-}$, and $\gamma$-HBCD using chiral permethylated $\beta$-cyclodextrin stationary phase (22). In the present paper, we report on the levels of HBCD diastereoisomers and their enantiomer fractions in shrimp and in muscle and liver of various fish species from the Western Scheldt Estuary (WSE). The WSE is highly contaminated with BFRs, possibly related to the presence of a BFR manufacturing plant, textile industries, and harbor activities located in the Scheldt Basin $(18,22,23)$.

\section{Experimental Section}

Sampling. The sampling of different marine species from the Western Scheldt Estuary (WSE) has been previously described (23). The selected sampling sites in the WSE (Figure 2) included two locations in the proximity of a HBCD production plant at Terneuzen, The Netherlands (locations 1 and 2), and three locations toward Antwerp, Belgium (locations $3-5$ ). The collected samples have previously been analyzed for PBDEs (23). Unfortunately, not all samples used in the previous study were available for this study. Muscle and liver of gadoids (whiting, Merlangius merlangus; bib, Trisopterus luscus) and flatfish (sole, Solea solea; plaice, Pleuronectus platessa), available from at least three locations, were pooled according to species and location using three to six individuals per pool. Muscle of individual eel (Anguilla anguilla) and pools of shrimps (Crangon crangon) were available from two locations (Table 1). Additionally, a cleaned sediment extract, which originated from the WSE (between Terneuzen and Antwerp), was used to assess the qualitative composition of HBCD diastereoisomers.

Chemicals. All solvents used for the sample preparation and cleanup ( $n$-hexane, acetone, iso-octane) were of SupraSolv grade (Merck, Darmstadt, Germany). Solvents used for LC/MS-MS (acetonitrile, methanol, water) were of HPLC grade (Merck). Individual HBCD diastereoisomers standards (CIL, Andover, USA) were used for identification and quantification. A HBCD technical mixture (melting point 188-191 ${ }^{\circ} \mathrm{C}$, Fluka, Buchs, Switzerland) and the technical mixture which was thermally equilibrated at $180^{\circ} \mathrm{C}$ for $2 \mathrm{~h}$ were used as in-house standards. Pure HBCD diastereoisomers isolated from a technical mixture were obtained from Andreas Gerecke (EMPA, Dübendorf, Switzerland). 2,5Dibromotoluene (Sigma-Aldrich, Milwaukee, WI) was used as an external standard.

Sample Preparation and Cleanup. The same extracts as those previously prepared for the determination of PBDEs (23) were used in this work. Briefly, the homogenized sample was dried with anhydrous sodium sulfate and Soxhlet extracted with hexane/acetone $(3: 1 ; v / v)$. After lipid determination, the extract was cleaned up on acidified silica and eluted with a mixture of hexane/dichloromethane. After solvent evaporation, the extract was dissolved in iso-octane and analyzed by GC/MS for PBDEs (23). After analysis, the vials were recapped and stored at $-20^{\circ} \mathrm{C}$. For the determination of HBCD diastereoisomers and enantiomers, the solvent was exchanged to acetonitrile $(140 \mu \mathrm{L})$ and $10 \mu \mathrm{L}$ of a solution of 2,5-dibromotoluene in acetonitrile (160 $\mu \mathrm{g}$ / $\mathrm{mL}$ ) was added as external standard.

Separation of HBCD Diastereoisomers. Liquid chromatography was performed using a HTC PAL autosampler (CTC Analytics AG, Zwingen, Switzerland) and a Surveyor liquid chromatographic pump (ThermoFinnigan, San Jose, CA). Separations were performed on a Symmetry $C_{18}(2.1 \times 150$ $\mathrm{mm}, 5 \mu \mathrm{m})$ column (Waters, Milford, MA). Samples ( $20 \mu \mathrm{L}$ ) were injected using a mobile phase containing water/ methanol/acetonitrile $(60 / 30 / 10)$ at a flow rate of $250 \mu \mathrm{L} /$ min. A linear gradient was used to methanol/acetonitrile (50/50) in $5 \mathrm{~min}$ and then the final composition was held for $6 \mathrm{~min}$.

Separation of HBCD Enantiomers. A chiral LC column $(4.0 \times 200 \mathrm{~mm}, 5 \mu \mathrm{m})$ containing permethylated $\beta$-cyclodextrin stationary phase NUCLEODEX beta-PM (MachereyNagel GmbH \& Co, Düren, Germany) was used. Samples (20 $\mu \mathrm{L}$ ) were injected using a mobile phase containing water/ methanol/acetonitrile $(40 / 30 / 30)$ at a flow rate of $500 \mu \mathrm{L} /$ min. Initial mobile phase composition was held for $0.5 \mathrm{~min}$ followed by a linear gradient to methanol/acetonitrile ( $30 /$ 70 ) in $8 \mathrm{~min}$ and then the final composition was held for 14 min.

MS Detection. A triple-stage quadrupole mass spectrometer TSQ Quantum (Thermo Finnigan) was operated in electrospray ionization negative ion mode using multiple reaction monitoring for $[\mathrm{M}-\mathrm{H}]^{-}(\mathrm{m} / \mathrm{z} 640.6) \rightarrow \mathrm{Br}^{-}(\mathrm{m} / z 79.0$ and 81.0 ) with a scan width of 0.8 mass units and scan time of $0.2 \mathrm{~s}$. The first and third quadrupoles were set to unit resolution. Argon of $99.999 \%$ purity was used as collision gas at a pressure of $1.2 \times 10^{-3}$ Torr and the collision energy was set to $-17 \mathrm{eV}$ and $-21 \mathrm{eV}$ for bromine ions at $\mathrm{m} / z 79.0$ and 


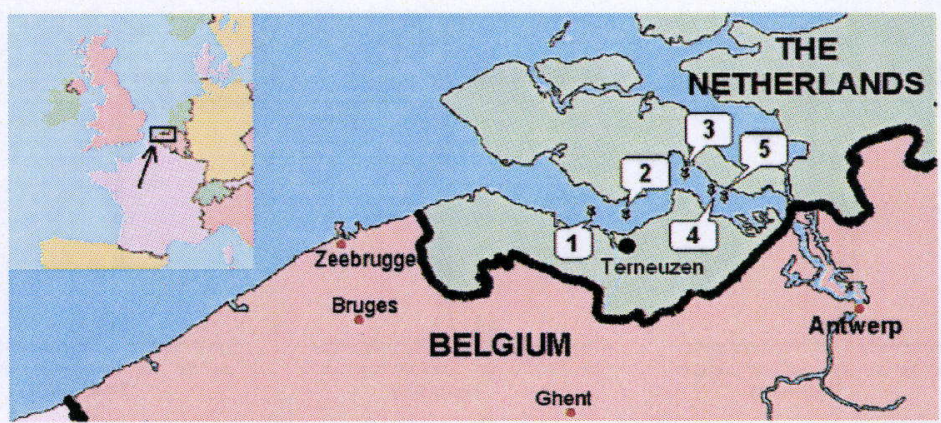

FIGURE 2. Map of the Western Scheldt Estuary showing the sampling locations.

TABLE 1. Concentrations of $\alpha-H B C D$ and $\gamma-K B C D$ Diastereoisomers in Shrimp and Fish Samples from the Western Scheldt Estuary (ng/g Lipid Weight)

\begin{tabular}{|c|c|c|c|c|c|c|c|c|c|c|c|c|c|c|c|c|c|c|c|c|}
\hline \multirow[b]{2}{*}{ location } & \multirow{2}{*}{\multicolumn{2}{|c|}{$\begin{array}{l}\text { shrimp } \\
\text { whole } \\
\end{array}$}} & \multirow{2}{*}{\multicolumn{2}{|c|}{$\frac{\text { eel }}{\text { muscle }}$}} & \multicolumn{4}{|c|}{ sole } & \multicolumn{4}{|c|}{ plaice } & \multicolumn{4}{|c|}{ bib } & \multicolumn{4}{|c|}{ whiting } \\
\hline & & & & & \multirow{2}{*}{\multicolumn{2}{|c|}{$\frac{\text { muscle }}{1.0}$}} & \multirow{2}{*}{\multicolumn{2}{|c|}{$\frac{\text { liver }}{13}$}} & \multirow{2}{*}{\multicolumn{2}{|c|}{$\frac{\text { muscle }}{0.8}$}} & \multirow{2}{*}{\multicolumn{2}{|c|}{$\begin{array}{c}\text { liver } \\
34 \\
\end{array}$}} & \multirow{2}{*}{\multicolumn{2}{|c|}{$\frac{\text { muscle }}{0.5}$}} & \multirow{2}{*}{\multicolumn{2}{|c|}{$\begin{array}{c}\text { liver } \\
54 \\
\end{array}$}} & \multirow{2}{*}{\multicolumn{2}{|c|}{$\frac{\text { muscle }}{0.4}$}} & \multirow{2}{*}{\multicolumn{2}{|c|}{$\begin{array}{c}\text { liver } \\
30 \\
\end{array}$}} \\
\hline lipids (\%) & & & 2 & & & & & & & & & & & & & & & & & \\
\hline 2 & & & & & 1100 & 13 & 680 & $<1$ & 38 & $<2$ & 26 & 6 & 53 & 43 & 150 & 5 & 75 & 38 & 170 & 9 \\
\hline 3 & 28 & 18 & 27 & 3 & 360 & 17 & 110 & 8 & & & & & 53 & $<3$ & 100 & 10 & 45 & $<3$ & 16 & $<3$ \\
\hline
\end{tabular}

81.0 , respectively. Optimization of the MS/MS conditions for $\gamma$-HBCD resulted in a spray voltage of $4000 \mathrm{~V}$, sheath gas flow of $60 \mathrm{psi}$, auxiliary gas flow of 5 psi, capillary temperature of $340^{\circ} \mathrm{C}$, tube lens offset of $-69 \mathrm{~V}$, lens zero offset of $1.3 \mathrm{~V}$, and an ion source collision-induced dissociation of $10 \mathrm{~V}$.

Quality Assurance. The quality control was done by repeated injections of solvent blanks (acetonitrile), in-house reference standards (such as a technical $\mathrm{HBCD}$ from Fluka, technical $\mathrm{HBCD}$ equilibrated at $180^{\circ} \mathrm{C}$ ), and of standards. The internal standards used for determination of PBDEs by GC (polybrominated biphenyl 103 and ${ }^{13} \mathrm{C}$-BDE 209) were not used and furthermore were not suitable for the LC conditions. Therefore, for the determination of $\mathrm{HBCD}$ diastereoisomers, an external standard was used. This procedure did not allow to correct for losses of $\mathrm{HBCD}$ diastereoisomers during the sample preparation. A mean recovery of $90 \%$ similar to what has been previously found for hexa-BDEs (23) was used for the calculation of $\mathrm{HBCD}$ levels. Analytes were positively identified if the absolute retention time agreed with the retention time of the corresponding individual HBCD standard within $2.5 \%$ for diastereoisomeric determination and within $1.8 \%$ for enantiomer determination. Calibration curves were made from standard solutions at seven $(2,5,10,20,50,100$, and $200 \mathrm{ng}$ diastereomer $\left./ \mathrm{mL} ; R^{2}=0.993-0.998\right)$ and $\operatorname{six}(2.5,5,10,20$, 50 , and $100 \mathrm{ng}$ enantiomer $/ \mathrm{mL} ; R^{2}=0.993-0.995$ ) concentration levels analyzed in triplicate for the determination of diastereoisomers and enantiomers, respectively. All samples were analyzed at least in duplicate by both reversed-phase LC and chiral LC. The instrumental limit of detection (LOD), defined as 3 times the noise level and based on the LC/MSMS performance, was $0.5,1$, and $5 \mathrm{pg}$ for $\gamma-\mathrm{HBCD}, \alpha-\mathrm{HBCD}$, and $\beta-H B C D$, respectively, while the method limits of quantification of diastereoisomers (LOQ, $S / N=10$ ) were 15 , 20 , and $75 \mathrm{pg} / \mathrm{g}$ wet weight ( $w w)$ for $\gamma-\mathrm{HBCD}, \alpha-\mathrm{HBCD}$, and $\beta$-HBCD, respectively. None of the analytes were detected in solvent blanks.

Enantiomer Fraction. The enantiomeric composition was expressed as enantiomer fractions (EFs) (20) calculated from the peak areas of the enantiomeric pairs by the following formula:

$$
\mathrm{EF}=\frac{(+) A}{(-) A+(+) A}
$$

According to Heeb et al. $(4),(-) \alpha,(-) \beta$, and $(+) \gamma$ are first eluting peaks from each corresponding enantiomer pair. Enantiomer fractions were reported as not estimated (n.e.) when the concentration of corresponding diastereoisomers was lower than the LOQ.

\section{Results and Discussion}

Despite the increasing interest in $\mathrm{HBCD}$, data on environmental occurrence of HBCD are still scarce. There is a need for more environmental and human monitoring, together with the investigation of exposure pathways and levels and with an imperious demand for data on the individual $\mathrm{HBCD}$ isomers. In the present work, we stress an extra dimension that it might be necessary to estimate the exposure and effects based not only on HBCD diastereoisomers but also on $\mathrm{HBCD}$ enantiomers.

Separation of Isomers. Several stationary phases were tested for the separation of the three HBCD diastereoisomers, $\mathrm{C} 18$ (three types), $\mathrm{C} 8$, phenyl, amide, and ether modified silica. A baseline separation was achieved using Waters' Symmetry $C_{18}$ (Figure 3). All three diastereoisomers may be separated using any ratio of methanol/acetonitrile as mobile phase. An increase in the percentage of acetonitrile in the mobile phase resulted in a slightly better separation of $\mathrm{HBCD}$ diastereoisomers, mainly between $\beta$-HBCD and $\gamma-\mathrm{HBCD}$. However, in this case, a lower sensitivity for $\alpha$-HBCD was observed while maintaining a similar sensitivity for $\gamma-\mathrm{HBCD}$. In contrast, baseline separation of HBCD enantiomers (Figure 4) on the chiral permethylated cyclodextrin column could be achieved only with the mobile phase composition given in the Fxperimental Section. 

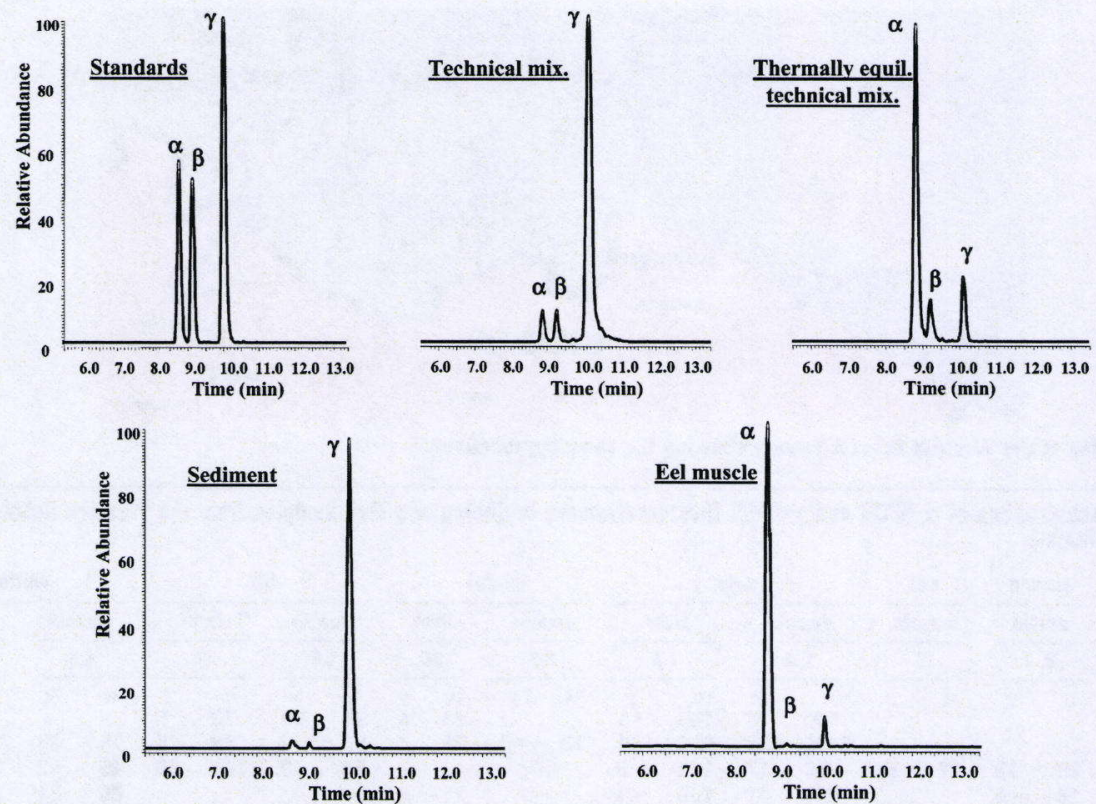

FIGURE 3. Chromatographic separation of HBCD diastereoisomers in standard mixture and biotic and abiotic samples.
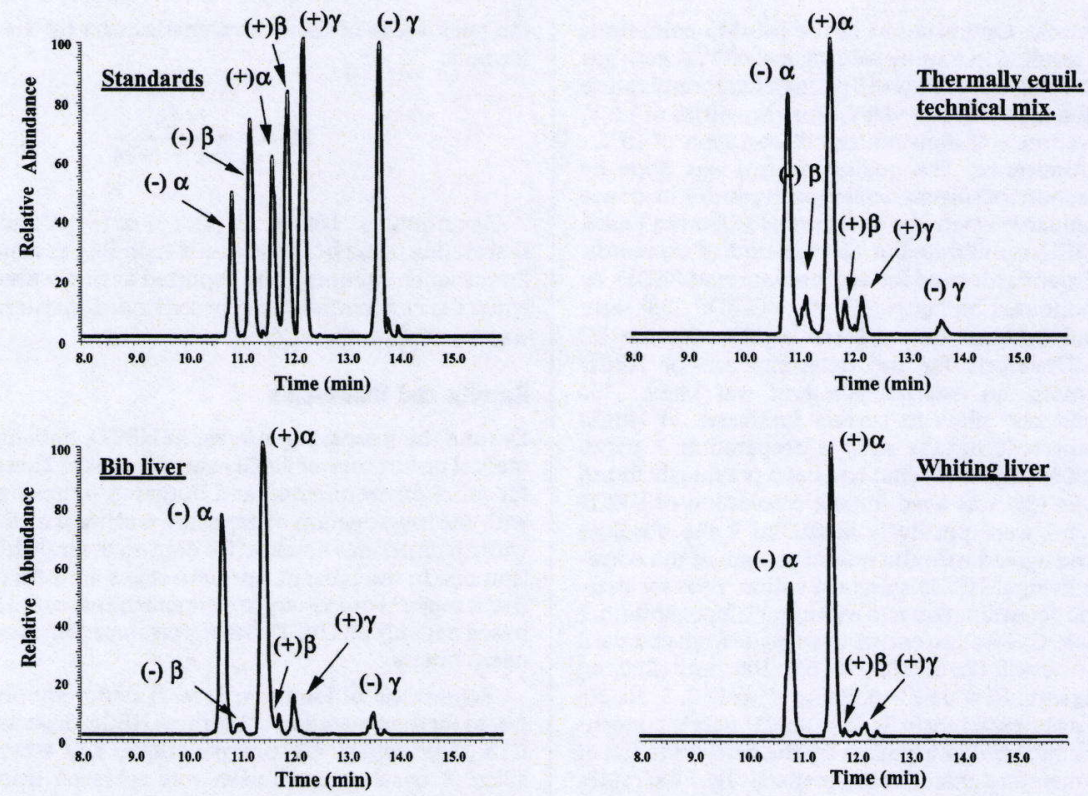

FIGURE 4. Chromatographic separation of HBCD enantiomers in a standard mixture and biotic and abiotic samples. Assignment of optical rotation according to Heeb et al. (4).

Levels of HBCD Diastereoisomers, $\alpha$-HBCD could be quantified in all 26 samples, while $\gamma$-HBCD was detected in $73 \%$ and quantified in $35 \%$ of all samples. $\beta$-HBCD could be detected at low levels in only $25 \%$ of the samples and could be quantified only in two bib liver samples (1.6 and $2.2 \mathrm{ng} / \mathrm{g}$ lipid weight) and one eel muscle sample $(3.4 \mathrm{ng} / \mathrm{g} \mathrm{lw})$. The concentrations of individual HBCD diastereoisomers in marine biota from the WSE are summarized in Table 1 .
Previously, high concentrations of PBDEs have been measured in fish samples and sediments from the WSE $(23,24)$ and were related to uses of PBDEs in various industries located in the Scheldt Basin. Because of the presence of a HBCD production plant (Broomchemie; 7500 tons $\mathrm{HBCD}$ / year) in Terneuzen, The Netherlands (Figure 2), it was suspected that HBCD may be present in fish samples at relatively high levels. In fact, $\mathrm{HBCD}$ levels found in fish from 


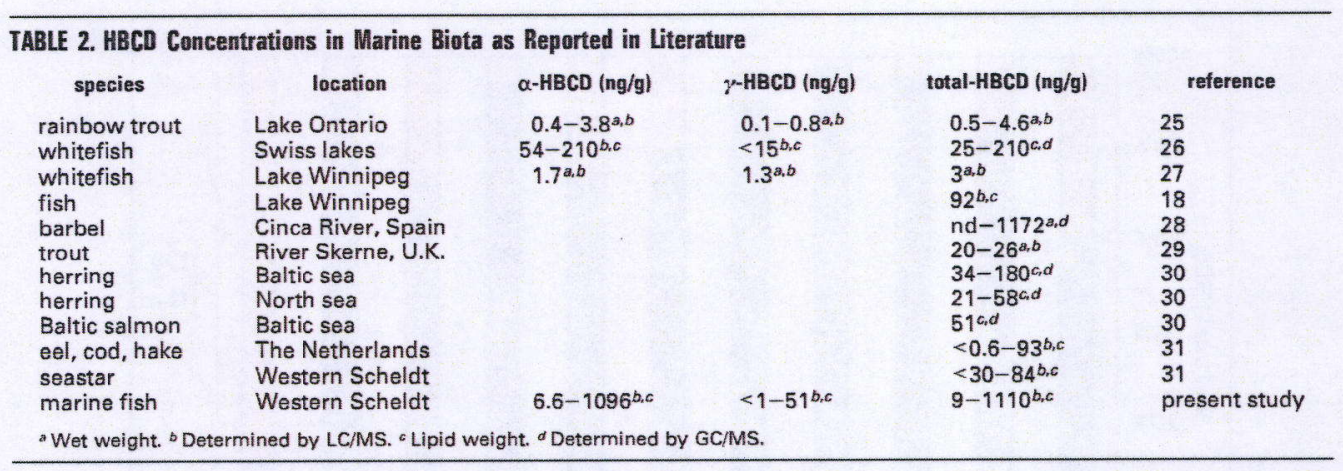

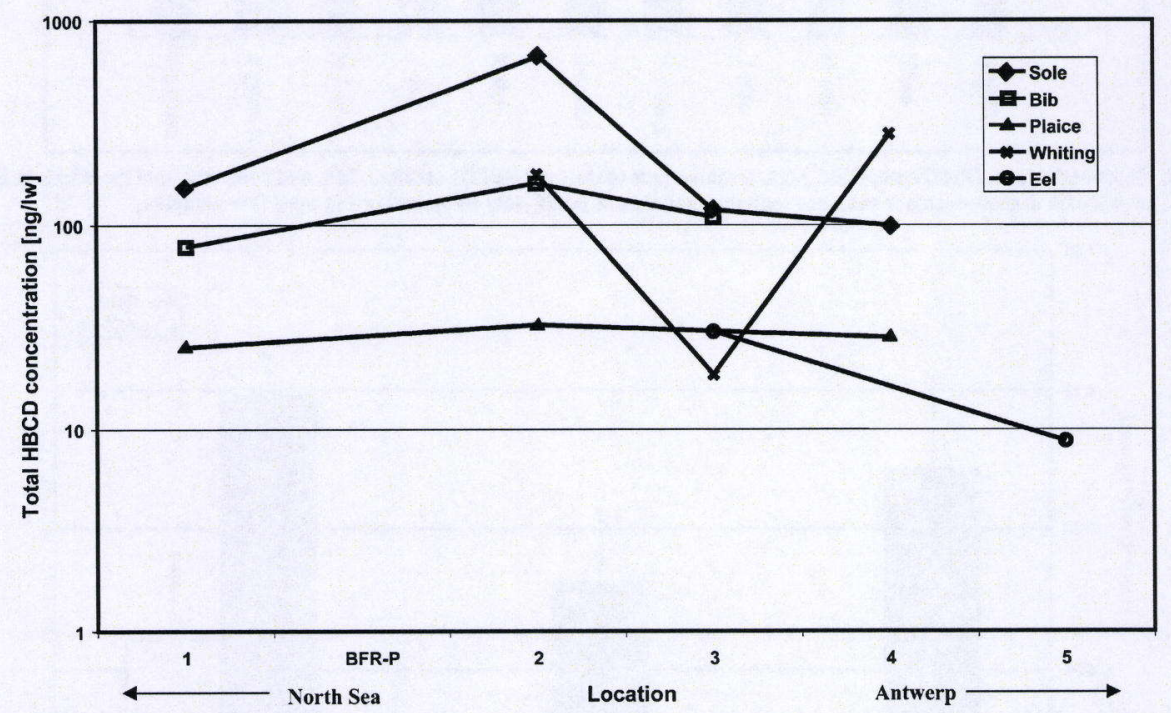

FIGURE 5. Total HBCD levels in liver of sole, bib, plaice, and whiting and in muscle of eel sampled at different locations of the Western Scheldt. BFR-P denotes the location of the BFR production plant (Terneuzen, The Netherlands).

the WSE were higher than levels found in fish samples from locations with no potential sources of $\mathrm{HBCD}$, representing mainly background contamination (Table 2). Much higher $\mathrm{HBCD}$ levels (up to $10000 \mathrm{ng} / \mathrm{g} w \mathrm{w}$ ) have been found in fish sampled near point sources of pollution in the United Kingdom (29) and in Sweden (32). However, because of the high water volume of the WSE and the high tidal flow, the actual HBCD levels in fish decreased with distance from Terneuzen (Figure 5), with the exception of whiting probably because of its more migratory character. Location 2 situated near the potential $\mathrm{HBCD}$ point source exhibited the highest HBCD levels in three out of four fish species. For fish species caught at the same location, the highest levels of total HBCD were found in sole (Table 1). In general, concentrations of $\mathrm{HBCD}$ in fish were about 5-10 times lower than those of PBDEs. Similar differences between the HBCD and PBDEs levels have been found by Gerecke et al. in whitefish from six Swiss lakes (26). No statistically significant correlations between total HBCD and PBDE concentrations were found at any location with the exception of location 4 , for which a high positive correlation $\left(r^{2}=0.97, p<0.01\right)$ was obtained. Location 4 is situated far enough from the potential point source, so that the HBCD levels in fish from this location are not affected by potential point source and may be considered as background level.
Since the first diastereoisomer-specific analysis of $\mathrm{HBCD}$ in biota $(26,29)$, it was recognized that the pattern of $H B C D$ diastereoisomers found in environmental samples may differ from those found in technical products (6). The diastereoisomer profile of $\mathrm{HBCD}$ in sediment samples was reported to be similar to that of commercial formulations $(17,33,34)$. Typically, as in Detroit River suspended sediments, the $\gamma$-isomer was the dominant diastereoisomer in most samples (33). While in sediments from the Drammen River, Norway, $\alpha-H B C D$ had comparable or higher levels than $\gamma-\mathrm{HBCD}(34)$, in fish (brown trout, perch, cod, flounder, eel) caught in the same area, only $\alpha-\mathrm{HBCD}(5-22 \mathrm{ng} / \mathrm{g}$ lw) could be measured (34). Similarly, we have found $\gamma$-HBCD to be the dominant isomer in sediment from the WSE (Figure 6), while $\alpha$-HBCD and $\beta-H B C D$ were present at much lower levels.

Recently, it was found that the ratio among the $\mathrm{HBCD}$ diastereoisomers might differ for the same species in different environments. While levels of $\alpha$-HBCD were consistently higher than $\gamma-\mathrm{HBCD}$ in whitefish from Lake Ontario (25), concentrations of $\alpha$-HBCD and $\gamma$-HBCD were similar in the same fish species from Lake Winnipeg (27). Moreover, in other species (walleye and burbot), $\gamma$-HBCD was at least twice as high as $\alpha$-HBCD, while $\beta$-HBCD was consistently detected in all analyzed fishes (27). In whitefish and sauger, the levels of $\alpha-\mathrm{HBCD}$ and $\gamma$-HBCD diastereoisomers were comparable, 


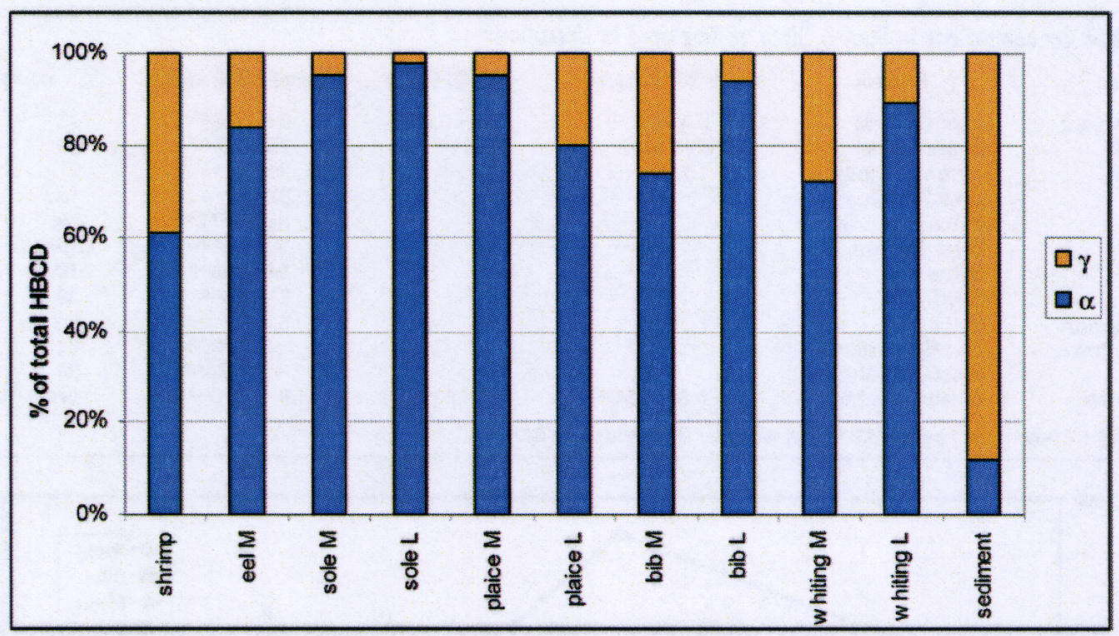

FIGURE 6. Contribution of $\alpha-\mathrm{HBCD}$ and $\gamma-\mathrm{HBCD}$ diastereoisomers to the total HBCD in shrimp, fish, and sediment from the Western Scheldt Estuary. The $\beta$-HBCD diastereoisomer was not included because it could only be quantified in very few samples.

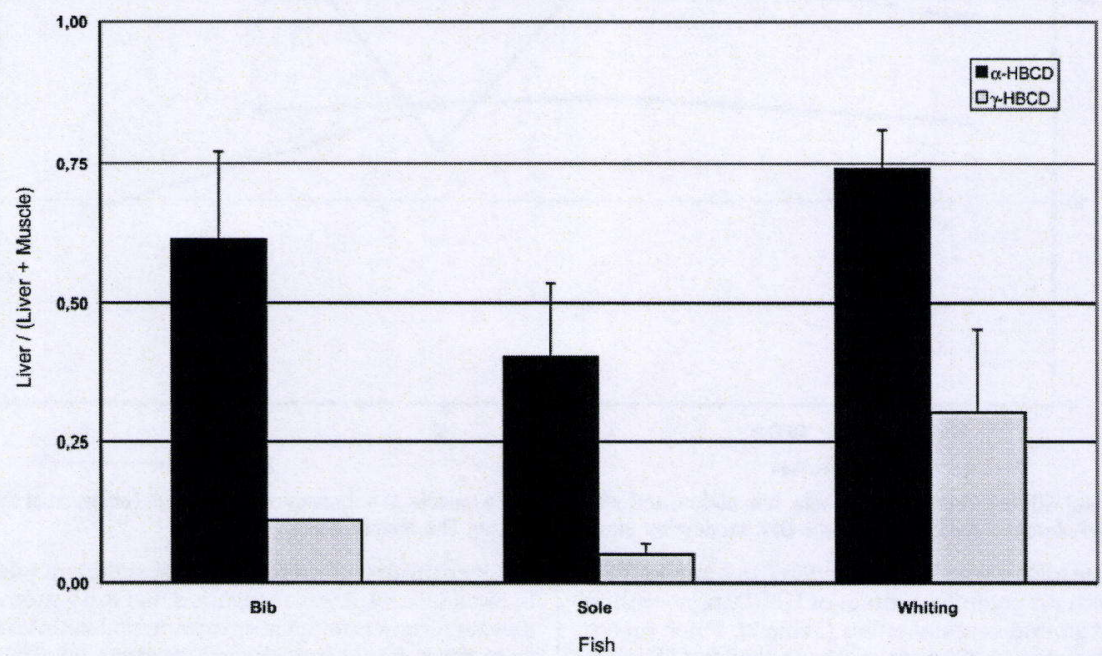

FIGURE 7. Liver accumulation ratio for $\alpha-H B C D$ and $\gamma-H B C D$ in different fish species; ratios higher than 0.50 indicate preferential liver accumulation.

while in plankton and goldeye, $\alpha-\mathrm{HBCD}$ was the dominant isomer, similar to what was observed in the present study. The present knowledge is too limited to point out the reason for such differences in the same fish species and in similar environments.

Accumulation of $\mathrm{HBCD}$ Diastereoisomers in Different Fish Tissues. The dominance of $\alpha$-HBCD over $\gamma$-HBCD in all fish species, in both muscle and liver, is demonstrated in Figure 6. Except for plaice, for which we had just one pair of liver and muscle, the ratio of $\alpha$ - to $\gamma$-HBCD is larger in liver than in muscle, with sole liver exhibiting total dominance of $\alpha$-HBCD over $\gamma$-HBCD. It seems that $\alpha$-HBCD is less metabolized in these fish than $\gamma$-HBCD.

To express the preferential tissue accumulation of a particular $\mathrm{HBCD}$ diastereoisomer, the concentration per lipid weight in liver was divided by the sum of concentrations in liver and muscle. For all species, $\gamma$-HBCD accumulated much less in liver than in muscle, that is, the ratio was below 0.5 .
For bib and whiting, a preferential accumulation in liver was observed for $\alpha-\mathrm{HBCD}$, while sole accumulated slightly more $\alpha$-HBCD in muscle (Figure 7). Plaice samples were too limited in number to evaluate this species. It can therefore be presumed that $\gamma$-HBCD is more easily metabolized in liver and that the metabolizing capacity for HBCD decreases from sole to bib and whiting. This is supported by a recent report which suggests that $\alpha-H B C D$ is much more resistant to biotransformation by liver microsomes than $\beta$ - and $\gamma$ - HBCD (14). However, a possible bioisomerization of $\gamma-\mathrm{HBCD}$ to $\alpha-\mathrm{HBCD}$ in liver cannot be excluded (10). A similar preferential liver accumulation as found here for $\alpha-\mathrm{HBCD}$ in bib and whiting and preferential muscle accumulation for $\alpha-H B C D$ in sole has also been observed for PBDEs (23).

Enantiomer Fractions of HBCD Diastereoisomers. By definition, the EF value for a racemic mixture is 0.50 . However, $\mathrm{EFs}$ of individual $\mathrm{HBCD}$ diastereoisomers isolated from a $\mathrm{HBCD}$ technical mixture were different from the $\mathrm{EF}$ of a 


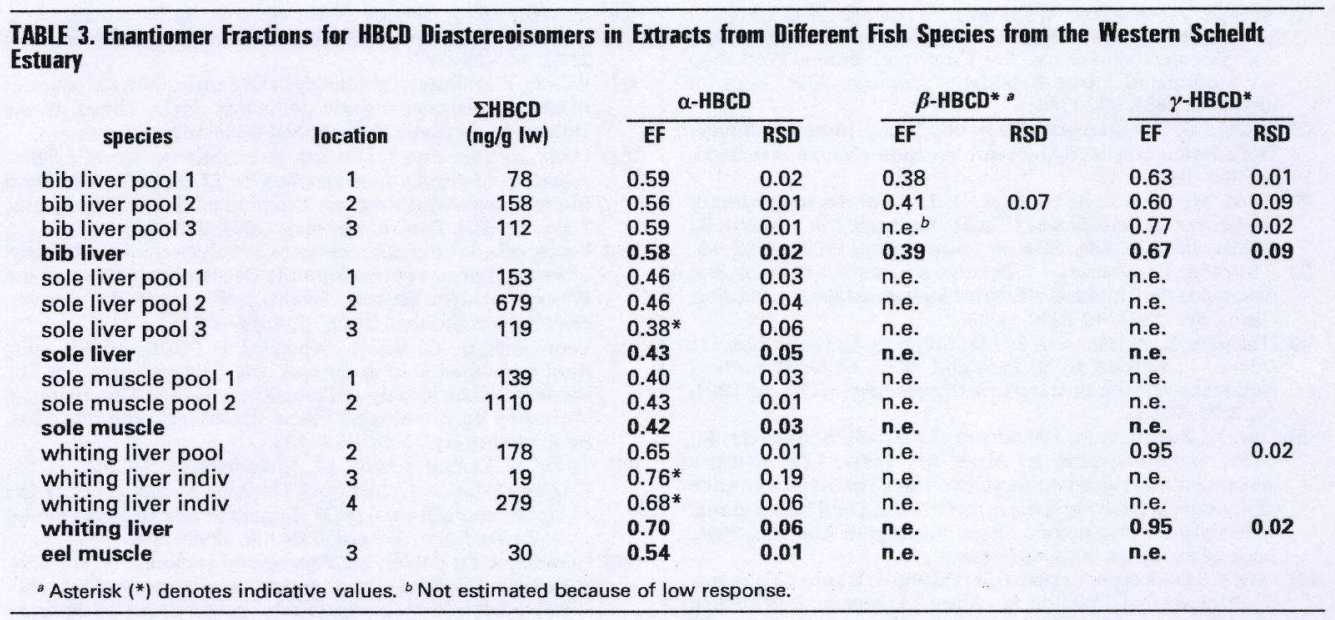

racemate, for example, $\mathrm{EF}=0.54 \pm 0.06$ for $\alpha-\mathrm{HBCD}$. Similarly, the analysis of commercially available individual $\mathrm{HBCD}$ diastereoisomers resulted in EFs higher than 0.50. A concentration dependence of the deviation from the racemic value was observed for $\alpha$ - HBCD ( $E F=0.51 \pm 0.02,0.54 \pm$ 0.02 , and $0.55 \pm 0.02$ for concentrations of 100,50 , and 25 $\mathrm{ng} / \mathrm{mL}$, respectively), but this was less obvious for $\beta$-HBCD and could not be seen for $\gamma$-HBCD. The deviation of the EFs from 0.50 could be due to a nonracemic composition of standards deriving from potentially enantioselective treatments during preparation and purification. On the other hand, the enantiomers eluting under slightly different conditions may show differential mass spectrometric response.

Because the analysis of purified racemic $\mathrm{HBCD}$ diastereoisomers from the different sources (EMPA, CIL) resulted in similar deviations of EFs, it was concluded that the deviations in EFs are most likely due to unequal response of the enantiomers. It is known that LC/MS is sensitive to matrix effects and that ionization may vary with respect to the sample composition. Further, ionization conditions may be different for the same compound peaks eluting sequentially out of the column into the ion source. Although EFs of standards were found slightly different from racemic composition, the observed deviation was not statistically significant and the RSDs observed for the triplicate analysis of each extract were higher than the apparent shift. Therefore, we present the EFs as they were calculated from peak areas without any correction. We have also found that the precision of EF determination dropped with decreasing analyte concentration (RSD > $10 \%$ for $10 \mathrm{ng} / \mathrm{mL}, 0.2 \mathrm{ng}$ injected) for all diastereoisomers. At concentrations below $5 \mathrm{ng} / \mathrm{mL}$ ( $0.1 \mathrm{ng}$ injected), the high RSDs observed ( $>25 \%$ ) resulted in a false average of EFs. Therefore, EFs are reported only for samples for which the injected amount of $\mathrm{HBCD}$ diastereoisomers was higher than $0.5 \mathrm{ng}$.

Because of a lower sensitivity of the enantiomer separation method and the fact that the same diastereoisomer is divided into two peaks, EFs could be calculated only for samples with concentrations of HBCD diastereoisomers above the LOQ. To reduce the uncertainty of the results, only peak areas above 7000 units were included in the calculation of EFs. The EFs for fish samples are presented in Table 3. Excluding plaice, EFs for $\alpha-\mathrm{HBCD}$ could be determined in most liver samples, in two sole muscle composites, and in one eel muscle. For bib and especially for whiting liver, a strong enrichment of the $(+) \alpha$-enantiomer was observed.
Sole was the only species for which we were able to determine the enantiomeric accumulation in both liver and muscle. It seems that enantiomer fractions are similar for liver and muscle, with a slight enrichment of (-) $\alpha$-enantiomer (Table $3)$. For eel muscle, no enantioselective accumulation of $\alpha-\mathrm{HBCD}$ was observed. Both $\beta$-HBCD and $\gamma$-HBCD concentrations were too low to calculate EFs with sufficient precision. EFs given for $\beta$-HBCD and $\gamma$-HBCD in bib liver and $\gamma$-HBCD in whiting liver are indicative values and subjected to relatively large uncertainty. Nevertheless, it seems consistent that EFs were $<0.5$ for $\beta$-HBCD and $>0.5$ for $\gamma$-HBCD. The toxicological significance for the enantioselective enrichment of HBCD diastereoisomers is so far not known. The EF often depends on the pollutant level in the organism; a higher pollutant level will often result in elevated biotransformation rates and thus in EFs different from $0.50(21)$. However, a slightly opposite trend is indicated by our data (Table 3 ). An explanation could lie in the rather low metabolic capacity of fish $(9,10)$. At a high $\mathrm{HBCD}$ concentration, it is possible that fish are not able to adequately metabolize the HBCD intake and the enantiomeric composition might approach racemic values.

In fish samples with high $\mathrm{HBCD}$ levels, a small additional peak eluting just after the first $(+) \gamma$-enantiomer was frequently detected, while in some samples, an additional peak eluted just before $(-) \gamma$-enantiomer from which it was often not fully separated. Recently, Heeb et al. (4) reported on two formerly unknown HBCD stereoisomers isolated from the technical product and assigned them as $\delta$ - and $\epsilon-\mathrm{HBCD}$. However, lacking the corresponding standards, it was not possible to confirm the identity of these additional peaks.

\section{Acknowledgments}

Dr. Andreas Gerecke (EMPA, Dübendorf, Switzerland) is acknowledged for the generous gift of pure HBCD diastereoisomers isolated from a technical mixture.

\section{Literature Cited}

(1) Bromine Science and Environmental Forum (BSEF). http:// www.bsef.com (accessed September 2004)

(2) Directive 2003/11/EC of the European Parliament and of the Council of 6 Feburary 2003 amending for the 24th time Council directive 76/769/EEC relating to restrictions on the marketing and use of certain dangerous substances and preparations (pentabromodiphenyl ether and octabromodiphenyl ether). Official Journal L 042, 15/02/2003.

(3) Kemmlein, S.; Herzke, D.; Law, R. J. BFR-governmental testing programme. Environ. Int. 2003, 29, 781-792.

VOL. 39, NO. 7, 2005 / ENVIRONMENTAL SCIENCE \& TECHNOLOGY = 1993 
(4) Heeb, N. V.; Schweizer, W. B.; Kohler, M.; Gerecke, A. C. 1,2,5,6,9,10-hexabromocyclododecane - a class of compounds with a complex stereochemistry. The Third International Workshop on Brominated Flame Retardants, Toronto, 2004, Book of abstracts, 2004, 337-340.

(5) Becher, G. The stereochemistry of 1,2,5,6,9,10-hexabromocyclododecane and its graphic representation. Chemosphere 2005 58, 989-991.

(6) Peled, M.; Scharia, R.; Sondack, D. Thermal rearrangement of hexabromo-cyclododecane (HBCD); Desmurs, J.-R., Gérard, B. Goldstein, M. J., Eds.; Elsevier: Amsterdam, 1995; pp 92-99.

(7) Barontini, F.; Cozzani, V.; Petarca, L. Thermal stability and decomposition products of hexabromocyclododecane. Ind. Eng. Chem. Res. 2003, 40, 3270-3280.

(8) Hunziker, R. W.; Gonsior, S.; MacGregor, J. A.; Desjardins, D. Ariano, J.; Friederich, U. Fate and effect of hexabromocyclododecane in the environment. Organohalogen Compd. 2004, $66,2300-2305$.

(9) Law, K.; Palace, V. P.; Halldorson, T.; Danell, R.; Wautier, K.; Evans, B.; Brinkworth, L.; Alaee, M.; Tomy, G. T. Dietary accumulation of hexabromocyclododecane isomers in juvenile rainbow trout (Oncorhynchusm mykiss). The Third International Workshop on Brominated Flame Retardants, Toronto, 2004, Book of abstracts, 2004, 433-436.

(10) Law, K.; Halldorson, T.; Danell, R.; Palace, V.; Wautier, K.; Evans, B.; Brinkworth, L.; Whittle, M.; Alaee, M.; Marvin, C. Evidence of bioisomerization of $\alpha$ - and $\gamma$-hexabromocyclododecane (HBCD) isomers in fish. The Third International Workshop on Brominated Flame Retardants, Toronto 2004, Book of abstracts, 2004, 383-386.

(11) Law, R. I.; Alaee, M.; Allchin, C. R.; Boon, J.P.; Lebeuf, M.; Lepom, P.; Stem, G. A. Levels and trends of polybrominated diphenylethers and other brominated flame retardants in wildlife. Environ. Int. 2003, 29, 757-770.

(12) de Wit, C. A. An overview of brominated flame retardants in the environment. Chemosphere 2002, 46, 583-624.

(13) Geyer, H. J.; Schramm, K.-W.; Darnerud, P. O.; Aune, M.; Feicht, E. A.; Fried, K. W.; Henkelmann, B.; Lenoir, D.; Schmid, P.; McDonald, T. A. Terminal elimination half-lives of the brominated flame retardants TBBPA, HBCD, and lower brominated PBDEs in humans. Organohalogen Compd. 2004, 66, 38673872 .

(14) Zegers, B. N.; Mets, A.; van Bommel, R.; Minkenberg, Ch.; Hamers, T.; Kamstra, J.H.; Learmont, J.A.; Vazquez, B. S.; Pierce, G.; Reid, B.; Patterson, T.; Rogan, E.; Murphy, S.; Addink, M. Hartmann, M. G.; Smeenk, Ch.; Dabin, W.; Ridoux, V.; González, A. F.; López, A.; Jauniaux, T.; Boon, J. P. Stereoisomer specific bioaccumulation of hexabromocyclododecane (HBCD) in marine mammals. The Third International Workshop on Brominated Flame Retardants, Toronto, 2004, Book of abstracts, 2004, nated Fla 414

(15) de Boer, J.; Law, R. J. Developments in the use of chromatographic techniques in marine laboratories for the determination of halogenated contaminants and polycyclic aromatic hydrocarbons. J. Chromatogr., A 2003, 1000, 223-251.

(16) Covaci, A.; Voorspoels, S.; de Boer, J. Determination of brominated flame retardants, with emphasis on polybrominated diphenyl ethers (PBDEs) in environmental and human samples - a review. Environ. Int. 2003, 29, 735-756.

(17) de Boer, J.; Allchin, C. R.; Zegers, B. N- Boon, J. P. Brandsma, S. H.; Morris, S. HBCD and TBBP-A in Sewage Sludge, Sediments and Biota, Including Interlaboratory Study, C033/02; Bromine service and Environmental Forum: Brussels, 2002.

(18) Budakowsk, W.; Tomy, G. Congener-specific analysis of hexabromocyclododecane by high-performance liquid chromatography/electrospray tandem mass spectrometry. Rapid Commun Mass Spectrom. 2003, 17, 1399-1404.

(19) Kallenborn, R.; Hühnerfuss, H. Chiral environmental pollutants; Springer-Verlag: Berlin, 2001.
(20) de Geus, H. J.; Wester, P. G.; de Boer, J.; Brinkman, U. A. Enantiomer fractions instead of enantiomer ratios. Chemosphere $2000,41,725-727$

(21) Wiberg, K. Enantiospecific analysis and environmental behavior of chiral persistent organic pollutants. Ph.D. Thesis, Umeå University, Sweden, 2001; ISBN91-7305-162-4.

(22) Janák, K.; Thomsen, C.; Becher, G. Enantiomer specific determination of HBCD diastereomers by LC-MS-MS. The Third International Workshop on Brominated Flame Retardants, Toronto, 2004, Book of abstracts, 2004, 313-316.

(23) Voorspoels, S.; Covaci, A.; Schepens, P. Polybrominated diphenyl ethers in marine species from the Belgian North Sea and the Western Scheldt Estuary: levels, profiles, and distribution. Environ. Sci. Technol. 2003, 37, 4348-4357.

(24) Voorspoels, S.; Covaci, A.; Schepens, P. PBDEs in sediments from a polluted area in Europe: the Belgian North Sea, the Western Scheldt Estuary and tributaries. The Third International Workshop on Brominated Flame Retardants, Toronto, 2004, Book of abstracts, 2004, 133-136

(25) Tomy, G. T.; Budakowski, W.; Halldorson, T.; Whittle, D. M.; Keir, M. J.; Marvin, C.; MacInnis, G.; Alaee, M. Biomagnification of alpha- and gamma-HBCD isomers in a Lake Ontario food web. Environ. Sci. Technol. 2004, 38, 2298-2303.

(26) Gerecke, A. C.; Kohler, M.; Zennegg, M.; Schmid, P.; Heeb, N. V. Detection of alpha-hexabromocyclododecane (HBCD isomer in Swiss fish at levels comparable to polybrominated diphenyl ethers (PBDEs). Organohalogen Compd. 2003, 61, 155-158.

(27) Tomy, G.; Halldorson, T.; Danell, R.; Law, K.; Stem, G.; Gerwutz, S.; Whittle, M.; Alaee, M.; Marvin, C. Hexabromocyclododecane ( $\mathrm{HBCD}$ ) isomers and brominated diphenyl ether (BDE) congeners in fish from Lake Winnipeg, Manitoba (Canada). The Third International Workshop on Brominated Flame Retardants, Toronto, 2004, Book of abstracts, 2004, 213-216.

(28) Eljarrat, E.; de la Cal, A.; Raldua, D.; Duran, C.; Barcelo, D Occurrence and bioavailability of Polybrominated Diphenyl Ethers and Hexabromocyclododecane in Sediment and Fish from the Cinca River, a Tributary of the Ebro River (Spain). Environ. Sci. Technol. 2004, 38, 2603-2608.

(29) Allchin, C. R.; Morris, S. Hexabromocyclododecane (HBCD) diastereoisomers and brominated diphenyl ether congener $(\mathrm{BDE})$ residues in edible fish from the rivers Skerne and Tees, U.K. Organohalogen Compd. 2003, 61, 41-44.

(30) Remberger, M.; Sternbeck, J.; Palm, A.; Kaj, L.; Strömberg, K. Brorström-Lundén, E. The environmental occurrence of hexabromocyclododecane in Sweden. Chemosphere 2004, 54, 9-21.

(31) Iaw, R. J; Allchin, C. R; de Boer, J- Covaci, A.; Herzke, D.; Lepom, P.; Morris, S.; de Wit, C. A. Levels and Trends of Brominated Flame Retardants in the European Environment. The Third International Workshop on Brominated Flame Retardants, Toronto, 2004, Book of abstracts, 2004, 79-104.

(32) Sellström, U.; Kierkegaard, A.; de Wit, C.; Jansson, B. Polybrominated diphenylethers and hexabromocyclododecane in sediment and fish from a Swedish river. Environ. Toxicol. Chem. 1998, 17, 1065-1072.

(33) Marvin, C.; Tomy, G.; Alaee, M.; MacInnis, G. Distribution of hexabromo-cyclododecane in Detroit River Suspended Sediments. The Third International Workshop on Brominated Flame Retardants, Toronto, 2004, Book of abstracts, 2004, 137-140.

(34) Schlabach, M.; Fjeld, E.; Borgen, A. R. Brominated Flame Retardants in Drammens River and the Drammensfjord, Norway. The Third International Workshop on Brominated Flame Retardants, Toronto, 2004, Book of abstracts, 2004, 147150.

Received for review September 26, 2004. Revised manuscript received December 11, 2004. Accepted December 20, 2004.

ES0484909 